\title{
A systematic review and meta-analysis of the effects of infliximab on the rate of colectomy and post-operative complications in patients with inflammatory bowel disease
}

\author{
Solmaz Ehteshami-Afshar ${ }^{1,2}$, Shekoufeh Nikfar ${ }^{3,4}$, Ali Rezaie ${ }^{5}$, Mohammad Abdollahi' $^{2,3}$
}

${ }^{1}$ Faculty of Medicine, Shahid Beheshti University of Medical Sciences, Tehran, Iran ${ }^{2}$ Faculty of Pharmacy, and Pharmaceutical Sciences Research Center, Tehran University of Medical Sciences, Iran

${ }^{3}$ Department of Pharmacoeconomics and Pharmaceutical Administration, Faculty of Pharmacy, Tehran University of Medical Sciences, Iran

${ }^{4}$ Food and Drug Laboratory Research Center, Food and Drug Organization, Ministry of Health and Medical Education, Tehran, Iran

${ }^{5}$ Department of Gastroenterology, University of Calgary, Alberta, Canada

Submitted: 20 August 2011

Accepted: 31 October 2011

Arch Med Sci 2011; 7, 6: 1000-1012

DOI: 10.5114/AOMS.2011.26612

Copyright $\odot 2011$ Termedia \& Banach

\section{Abstract}

Introduction: Use of biological therapies may reduce or delay the surgical procedures in patients with inflammatory bowel disease (IBD). The aim of this metaanalysis and systematic review was to determine the impact of pre-operative infliximab (IFX) use on the rate of surgical interventions in patients with IBD and also the effect of preoperative IFX therapy on post-surgical complications. Material and methods: Literature was searched for studies that investigated the efficacy of IFX on the rate of colectomy and post-operative complications/side effects in patients with IBD between 1966 and February 2011.

Results: Twelve articles were included in the meta-analysis. In comparison to control groups, patients who received IFX had a relative risk (RR) of 1.17 $(p=0.65)$ for the rate of colectomy, odds ratio of $3.34(p=0.09)$ in seven observational studies and RR of $0.74(p=0.79)$ in clinical trials for mortality. Summary RR of hospitalization was $0.61(p=0.005)$. Infections and anastomotic leak, pouch-related complications, sepsis and thrombotic events were more common in the patients under IFX therapy but post-operational hospitalization was lower. The patients with IBD who were under IFX therapy were most of the times refractive to other therapies and their disease was more severe.

Conclusions: Although IFX does not decrease the rate of colectomy in patients with IBD, it would not increase most of the post-operational side effects in the patients.

Key words: systematic review, meta-analysis, infliximab, anti-TNF, colectomy, postoperative complications, inflammatory bowel disease.

\section{Introduction}

Inflammatory bowel disease (IBD) is characterized by severe and progressive inflammation in the gastrointestinal (GI) tract, and includes the two main clinicopathological subtypes of ulcerative colitis (UC) and Crohn's

\author{
Corresponding author: \\ Prof. Mohammad Abdollahi \\ Faculty of Pharmacy, \\ and Pharmaceutical Sciences \\ Research Center \\ Tehran University \\ of Medical Sciences \\ Tehran 1417614411, Iran \\ E-mail: \\ mohammad@tums.ac.ir
}


disease (CD). Various medical treatments have been shown to be effective in management of IBD [1, 2]. Current medical treatments for IBD generally include sulfasalazine [3], 5-aminosalicylates [4], corticosteroids, immunomodulators $[5,6]$ and biological therapy [7]. Even with optimized medical therapy, $30-40 \%$ of patients with UC and $70-80 \%$ of patients with $C D$ may need surgery at some point during the course of their disease [8, 9]. Although surgery may lead to relief of symptoms and withdrawal of potentially toxic medication, several complications including anastomosis leakage, pelvic abscess, wound infection, small bowel obstruction, bleeding, and faecal incontinence may occur postoperatively [9]. Pre-operative use of immunomodulators and biological agents such as infliximab (IFX) by suppression of the immune response potentially increases the risk for postoperative infectious complications $[9,10]$. Increase in postoperative infection by other immunomodulators such as glucocorticoids and tacrolimus has been clearly shown [10]. On the other hand, there is clinical evidence that the use of IFX has reduced or delayed surgical interventions in IBD patients [11, 12]. A previous meta-analysis of the effect of IFX on short-term post-operative complications in patients with UC has demonstrated that short-term complications were increased by use of IFX but infectious complications and non-infectious complications were not significantly increased separately [13]. In the previous meta-analysis, five studies, published between 1966 and September 2009, were included and the effect of IFX on the rate of colectomy was not analysed.

The aim of this meta-analysis and systematic review was to determine the impact of pre-operative IFX use on the rate of colectomy in patients with IBD. We also intended to evaluate the effect of preoperative IFX therapy on surgical complications.

\section{Material and methods}

\section{Data sources}

PubMed, Scopus, Web of Science, and Cochrane Central Register of Controlled Trials were searched for studies that investigated the efficacy of IFX on the rate of colectomy and post-operative complications/side effects in patients with IBD. Data were collected from 1966 to February 2011. The search terms were "ulcerative colitis" and "Crohn" and "infliximab" and "colectomy" and also their abbreviations were applied. The terms "surgery" and "operation" and "IBD" were alternative keywords for additional relevant articles. For PubMed, all relevant MeSH terms were used. The final queries were validated by manual review and matching results. The reference lists from retrieved articles were also evaluated to make sure all applicable studies were included. The conference proceedings were also searched. The key outcome of interest was rate of colectomy and post-surgical adverse events.

\section{Study selection}

Studies that investigated the effectiveness and influence of IFX on the rate of colectomy and/or post-operative adverse events in patients with IBD were considered. Operational procedures on side effects such as fistuloplasty were not the outcome of interest and they were excluded. Three reviewers independently reviewed the title and abstract of each article to eliminate duplicates, reviews, case studies, trials that did not have institutional review board approval and uncontrolled trials and those published in languages other than English. Studies which were clinical trials, cohorts and case matched were included. Disagreements between reviewers were resolved by consensus. Data on patients' characteristics, therapeutic regimens, dosage, sample size, trial duration, and outcome measures were extracted.

\section{Assessment of trial quality}

The methodological quality of the included clinical trials was evaluated using the Jadad score, which assesses the descriptions of randomization, blinding, and dropouts (withdrawals) in the trials [14] (Table I), using the following dichotomized parameters (yes $=1$; no $=0$ ): randomization, whether randomization was described appropriately, double-blinding, whether double blinding was described appropriately, and whether dropouts (withdrawals) were described. The overall Jadad score ranged from 0 to 5 points (score $\leq 2$ low quality; $\geq 3$ high quality).

\section{Statistical analysis}

Data from selected studies were extracted into $2 \times 2$ tables. All included studies were weighted and pooled. Data were analysed using StatsDirect version 2.7.8. Odds ratio (OR) and 95\% confidence intervals $(95 \% \mathrm{Cl})$ were calculated using the Mantel-Haenszel and Der Simonian-Laird methods. The Cochran Q test was used to test heterogeneity. The event rate in the experimental (intervention) group against the event rate in the control group was calculated using l'Abbe plot as an aid to explore the heterogeneity of effect estimates. Funnel plot analysis was used as a publication bias indicator.

\section{Results}

The electronic searches yielded 664 items; 113 from PubMed, 17 from Cochrane Central, 51 from Web of Science, and 483 from Scopus. Of these, 14 
Table I. Jadad score of clinical trials

\begin{tabular}{|lcccc|}
\hline References & Randomization & Blinding & Withdrawals and dropouts & Total Jadad score \\
\hline Gustavsson et al. & 1 & 0 & 1 & 2 \\
\hline Jarnerot et al. & 2 & 2 & 1 & 5 \\
\hline Sandborn et al. & 1 & 1 & 1 & 3 \\
\hline
\end{tabular}

articles were scrutinized in full text. Two reports were considered ineligible. The included studies comprised 3 randomized clinical trials (RCTs), 8 cohort, and one case-matched retrospective study. In RCTs, 818 patients with UC were randomized to receive IFX or placebo $[12,15,16]$. Cohort studies represented 1915 patients, of whom 336 were treated with IFX [9-11, 17-21]. In one case-matched retrospective study, 46 out of 92 patients were treated with IFX [22] (Table II and Figure 1).

\section{Effectiveness of infliximab compared to placebo in colectomy in patients with ulcerative colitis}

The summary RR for colectomy in 3 RCTs $[12,15$, 16] was 1.17 with a $95 \% \mathrm{Cl}$ of $0.6-2.28$ and a nonsignificant RR ( $p=0.65$, Figure $2 \mathrm{~A}$ ). The Cochrane $Q$ test for heterogeneity indicated that the studies are heterogeneous ( $p=0.02$, Figure 2 B) and could not be combined. Thus the random effects for individual and summary of RR was applied. Regression of normalized effect vs. precision for all included studies for colectomy among IFX vs. placebo therapy could not be calculated because of too few included studies.

\section{Post-colectomy complications in patients who} received IFX compared to those who did not

\section{Mortality}

Summary OR of mortality in seven observational studies [9-11, 17, 18, 21, 22] was 3.34 with a $95 \% \mathrm{Cl}$ of 0.94-11.86, a non-significant OR ( $p=0.09$, Figure $3 \mathrm{~A}-\mathrm{a}$ ). The Cochrane $\mathrm{Q}$ test for heterogeneity indicated that the studies are homogeneous ( $p=0.97$, Figure $3 \mathrm{~A}-\mathrm{b})$ and could be combined; thus the fixed effects for individual and summary of OR was applied. Regression of normalized effect vs. precision for all included studies for mortality among IFX vs. placebo therapy was $-0.75(95 \% \mathrm{Cl}$ $=-2.94$ to $1.45, p=0.42$ ) and Kendall's test on standardized effect vs. variance indicated tau $=-0.14$, $p=0.56$ (Figure $3 \mathrm{C}$ ).

Summary RR of mortality in 3 RCTs $[12,15,16]$ was 0.74 with a $95 \% \mathrm{Cl}$ of $0.08-6.83$, a non-significant RR ( $p=0.79$, Figure $3 \mathrm{~B}-\mathrm{a})$. The Cochrane Q test for heterogeneity indicated that the studies are homogeneous ( $p=0.97$, Figure $3 \mathrm{~B}-\mathrm{b}$ ) and could be combined; thus the fixed effects for individual and summary of RR was applied. Regression of normalized effect vs. precision for all included studies for mortality among IFX vs. placebo therapy could not be calculated because of too few included studies.

\section{Hospitalization}

Summary RR of hospitalization in two RCTS [12, 15] was 0.61 with a $95 \% \mathrm{Cl}$ of $0.44-0.86$, a significant RR ( $p=0.005$, Figure 4 A). The Cochrane Q test for heterogeneity indicated that the studies are homogeneous ( $p=0.31$, Figure $4 \mathrm{~B}$ ) and could be combined but because of few included studies, the random effects for individual and summary of RR was applied. Regression of normalized effect vs. precision for all included studies in the outcome of hospitalization among IFX vs. placebo therapy could not be calculated because of too few included studies.

\section{Infectious complication}

Summary OR of infectious complication in nine observational studies [9-11, 17-22] was 1.56 with a $95 \% \mathrm{Cl}$ of $0.71-3.44$, a non-significant OR $(p=0.27$, Figure $5 \mathrm{~A}-\mathrm{a})$. The Cochrane $\mathrm{Q}$ test for heterogeneity indicated that the studies are heterogeneous ( $p<0.0001$, Figure 5 A-b) and could not be combined; thus the random effects for individual and summary of OR was applied. Regression of normalized effect vs. precision for all included studies in the outcome of infectious complication among IFX vs. placebo therapy was $-1.08(95 \% \mathrm{Cl}=$ -6.02 to 3.86, $p=0.62$ ) and Kendall's test on standardized effect vs. variance indicated tau $=-0.11$, $p=0.61$ (Figure $5 \mathrm{C}$ ).

Summary RR of infectious complication in two clinical trials $[15,16]$ was 0.37 with a $95 \% \mathrm{Cl}$ of $0.09-1.44$, a non-significant RR ( $p=0.15$, Figure $5 \mathrm{~B}-\mathrm{a})$. The Cochrane $\mathrm{Q}$ test for heterogeneity indicated that the studies are not heterogeneous ( $p=0.9013$, Figure $5 \mathrm{~B}-\mathrm{b}$ ) and could be combined but because of few included studies, the random effects for individual and summary of RR was applied. Regression of normalized effect vs. precision for all included studies in the outcome of infectious complication among IFX vs. placebo therapy could not be calculated because of too few included studies. 
Table II. Characteristics of studies included in the meta-analysis

\begin{tabular}{|c|c|c|c|c|c|c|c|}
\hline \multirow[t]{2}{*}{ References } & \multirow[t]{2}{*}{ Type of study } & \multirow[t]{2}{*}{ Inclusion criteria } & \multicolumn{2}{|c|}{ Number of patients } & \multirow{2}{*}{$\begin{array}{c}\text { Concomitant } \\
\text { therapy }\end{array}$} & \multirow{2}{*}{$\begin{array}{l}\text { Duration of } \\
\text { IFX therapy }\end{array}$} & \multirow{2}{*}{$\begin{array}{l}\text { Dosage } \\
\text { of IFX }\end{array}$} \\
\hline & & & $\begin{array}{l}\text { Received } \\
\text { IFX }\end{array}$ & $\begin{array}{l}\text { Did not } \\
\text { receive } \\
\text { IFX }\end{array}$ & & & \\
\hline \multirow{2}{*}{$\begin{array}{l}\text { Ferrante } \\
\text { et al. [9] }\end{array}$} & \multirow[t]{2}{*}{ Cohort } & \multirow{2}{*}{$\begin{array}{c}\text { UC } \\
\text { IBD type unclassified }\end{array}$} & 141 & & \multirow{2}{*}{$\begin{array}{l}\text { AZA, 6-MP, } \\
\text { MTX, CsA, CS }\end{array}$} & \multirow{2}{*}{$\begin{array}{l}12 \text { weeks prior } \\
\text { to primary }\end{array}$} & \multirow[t]{2}{*}{ NA } \\
\hline & & & 22 & 119 & & & \\
\hline \multirow{2}{*}{$\begin{array}{l}\text { Gustavsson } \\
\text { et al. [15] }\end{array}$} & \multirow[t]{2}{*}{$\mathrm{RCT}$} & \multirow{2}{*}{$\begin{array}{c}\text { Steroid refractory } \\
\text { UC }\end{array}$} & 45 & & \multirow{2}{*}{$\begin{array}{c}\text { Immunomodulator, } \\
\text { 5-ASA }\end{array}$} & \multirow{2}{*}{$\begin{array}{l}\text { Data not } \\
\text { available }\end{array}$} & \multirow[t]{2}{*}{$5 \mathrm{mg} / \mathrm{kg}$} \\
\hline & & & 24 & 21 & & & \\
\hline \multirow{2}{*}{$\begin{array}{l}\text { Mor } \\
\text { et al. [22] }\end{array}$} & \multirow{2}{*}{$\begin{array}{l}\text { Case matched } \\
\text { retrospective } \\
\text { study }\end{array}$} & \multirow{2}{*}{$\begin{array}{l}\text { UC, indeterminate } \\
\text { colitis }\end{array}$} & 92 & & \multirow[t]{2}{*}{$\mathrm{CS}, \mathrm{CsA}, 6-\mathrm{MP}$} & \multirow{2}{*}{$\begin{array}{l}\text { More than } \\
16 \text { week } \\
\text { preoperatively }\end{array}$} & \multirow[t]{2}{*}{ NA } \\
\hline & & & 46 & 46 matched & & & \\
\hline \multirow{2}{*}{$\begin{array}{l}\text { Kunitake } \\
\text { et al. [10] }\end{array}$} & \multirow[t]{2}{*}{ Cohort } & \multirow{2}{*}{$\begin{array}{c}\mathrm{UC}, \mathrm{CD} \\
\text { indeterminate colitis }\end{array}$} & 413 & & \multirow[t]{2}{*}{ CS, AZA, 6-MP } & \multirow{2}{*}{$\begin{array}{c}12 \text { weeks } \\
\text { before surgery }\end{array}$} & \multirow{2}{*}{$\begin{array}{l}5 \text { or } 10 \\
\mathrm{mg} / \mathrm{kg}\end{array}$} \\
\hline & & & 101 & 312 & & & \\
\hline \multirow{2}{*}{$\begin{array}{l}\text { Marchal } \\
\text { et al. [17] }\end{array}$} & Cohort & $C D$ & 79 & & AZA, CS, ASA, & Data not & $5 \mathrm{mg} / \mathrm{kg}$ \\
\hline & & & 40 & 39 & $\begin{array}{l}\text { MTX, antibiotic, } \\
\text { budesonide }\end{array}$ & available & \\
\hline Bordeianou & Cohort & Ulcerative or & 171 & & $\mathrm{CS}, 6-\mathrm{MP}$ & Within 12 weeks & NA \\
\hline et al. [11] & & indeterminate colitis & 44 & 127 & imuran, AZA & prior to surgery & \\
\hline Schluender & Cohort & UC & 151 & & $\mathrm{CS}, 6-\mathrm{MP}$ & Median of two & NA \\
\hline et al. [18] & & & 17 & 134 & 6-TG, CsA & $\begin{array}{c}\text { (range 1-12) } \\
\text { months } \\
\text { before surgery }\end{array}$ & \\
\hline Colombel & Cohort & $C D$ & 270 & & CS, & Within 8 weeks & $\mathrm{s} 5 \mathrm{mg} / \mathrm{kg}$ \\
\hline & & & 52 & 218 & & $\begin{array}{l}\text { before surgery } \\
\text { or within } \\
30 \text { days } \\
\text { after surgery }\end{array}$ & \\
\hline Appau & Cohort & $C D$ & 389 & & ASA, AZA, MTX, & Data & NA \\
\hline et al. [20] & & & 60 & 329 & & not available & \\
\hline Selvasekar & Cohort & Chronic UC & 301 & & CS, AZA, 5-ASA & 2-6 months & NA \\
\hline et al. [21] & & & 47 & 254 & & $\begin{array}{l}\text { prior to the } \\
\text { surgery }\end{array}$ & \\
\hline Jarnerot & $\mathrm{RCT}$ & UC & 45 & & CS & 3 months & $4-5 \mathrm{mg} / \mathrm{kg}$ \\
\hline & & & 24 & 21 & & & \\
\hline Sandborn & RCT & UC & 728 & & CS, AZA, & 54 weeks & 5 or 10 \\
\hline et al. [12] & & & 484 & 244 & & & \\
\hline
\end{tabular}

$R C T$ - randomized controlled trial, UC - ulcerative colitis, CD - Crohn's disease, 5-ASA - 5-aminosalicylates, CS - corticosteroids, AZA - azathioprine, 6-MP - 6-mercaptopurine, CSA-cyclosporine A, 6-TG - 6-thioguanine, MTX - methotrexate, NA - not available

\section{Early post-operative complication}

Summary OR of early post-operative complication in two observational studies [17, 22] was 2.11 with a $95 \% \mathrm{Cl}$ of $1.02-4.36$, a significant OR $(p=0.04$, Figure $6 \mathrm{~A})$. The Cochrane $\mathrm{Q}$ test for heterogeneity indicated that the studies are not heterogeneous ( $p=0.34$, Figure $6 \mathrm{~B}$ ) and could be combined but because of few included studies, the random effects for individual and summary of OR was applied. Regression of normalized effect vs. precision for all included studies in the outcome of early post-operative complication among IFX vs. place- bo therapy could not be calculated because of too few included studies.

\section{Late post-operative complication}

Summary OR of late post-operative complication in two observational studies [17, 22] was 1.57 with a $95 \% \mathrm{Cl}$ of 0.8-3.06, a non-significant OR ( $p=0.19$, Figure $7 \mathrm{~A}$ ). The Cochrane Q test for heterogeneity indicated that the studies are not heterogeneous ( $p=0.49$, Figure $7 \mathrm{~B}$ ) and could be combined but because of few included studies, the random effects for individual and summary of OR was applied. 
Regression of normalized effect vs. precision for all included studies in the outcome of late post-operative complication among IFX vs. placebo therapy could not be calculated because of too few included studies.

\section{Post-operative side effects in patients with inflammatory bowel disease who took infliximab pre-operatively and those who did not}

\section{Anastomotic leak}

Summary OR for anastomotic leak in seven observational studies [9-11, 17, 20-22] was 1.71 with a $95 \% \mathrm{Cl}$ of $1.02-2.87$, a significant OR $(p=0.05)$ (Table III). The Cochrane Q test for heterogeneity indicated that the studies are not heterogeneous ( $p=0.07)$ and could be combined; thus the fixed effects for individual and summary of OR was applied. Regression of normalized effect vs. precision for all included studies in the outcome of anastomotic leak among IFX vs. placebo therapy was $1.69(95 \% \mathrm{Cl}=-5.29$ to $1.92, p=0.28)$ and Kendall's test on standardized effect vs. variance indicated tau $=-0.43(p=0.14)$.

\section{Pelvic abscess}

Summary OR for pelvic abscess in two observational studies $[9,21]$ was 1.09 with a $95 \% \mathrm{Cl}$ of $0.17-6.93$, a non-significant OR $(p=0.93)$. The Cochrane $\mathrm{Q}$ test for heterogeneity indicated that the studies are not heterogeneous $(p=0.15)$ and could be combined but because of few included studies the random effects for individual and summary of OR was applied. Regression of normalized effect vs. precision for all included studies in the outcome of pelvic abscess among IFX vs. placebo

Relative risk meta-analysis plot (random effects)

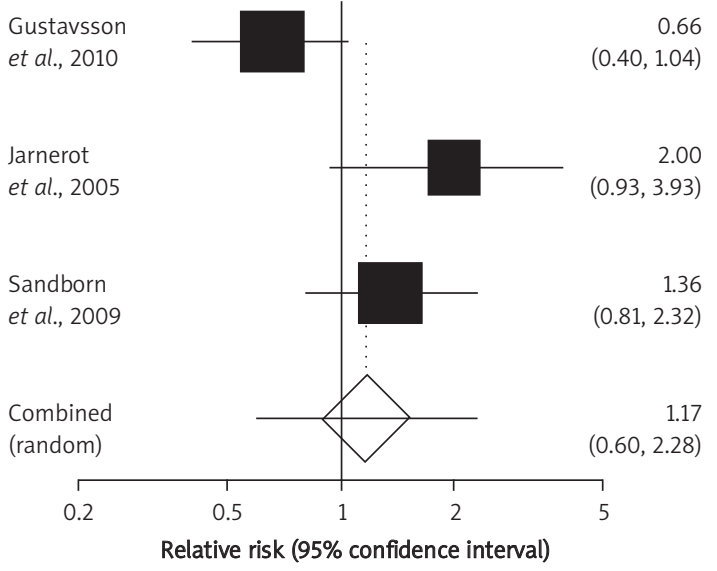

Figure $2 \mathrm{~A}$. Individual and pooled relative risk for the outcome of "colectomy" in the clinical trials considering IFX vs. placebo therapy

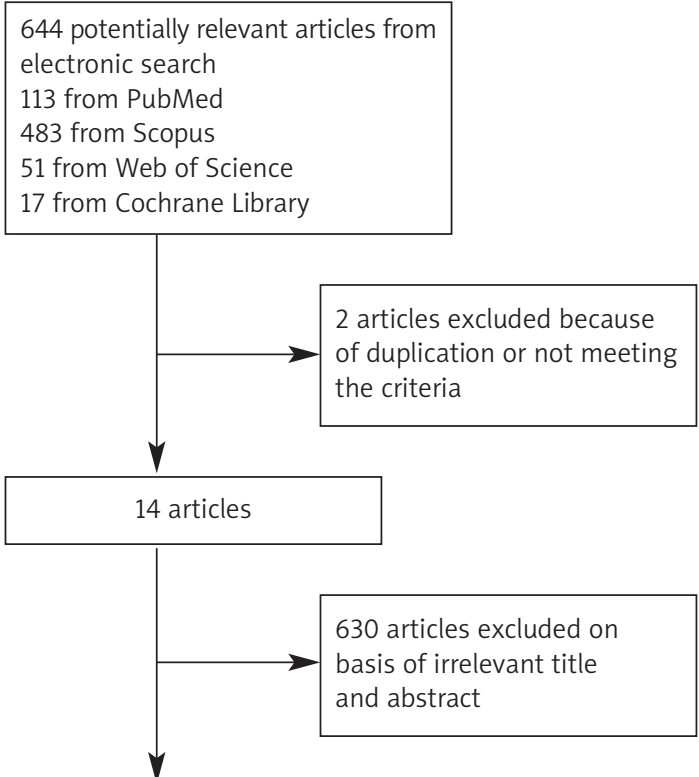

12 articles included and meta-analysed

Figure 1. Flow diagram of the study selection process

therapy could not be calculated because of too few included studies.

\section{Pouch-related complications}

Summary OR for pouch-related complications in three observational studies [9, 21, 22] was 2.06 with a $95 \% \mathrm{Cl}$ of $1.16-3.66$, a significant OR $(p=0.023)$. The Cochrane Q test for heterogeneity indicated that the studies are not heterogeneous ( $p=0.054$ ) and could be combined; thus the fixed effects for individual and summary of OR was applied. Regression of normalized effect vs. precision for all includ- 
Odds ratio meta-analysis plot (fixed effects)

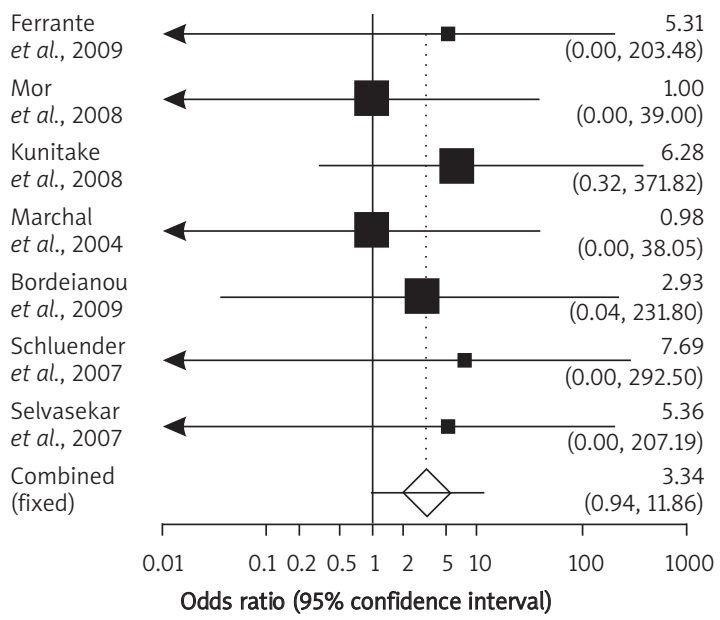

Figure $3 \mathrm{~A}-\mathrm{a}$. Individual and pooled odds ratio for the outcome of "mortality" in the observational studies considering IFX vs. placebo therapy

Relative risk meta-analysis plot (fixed effects)

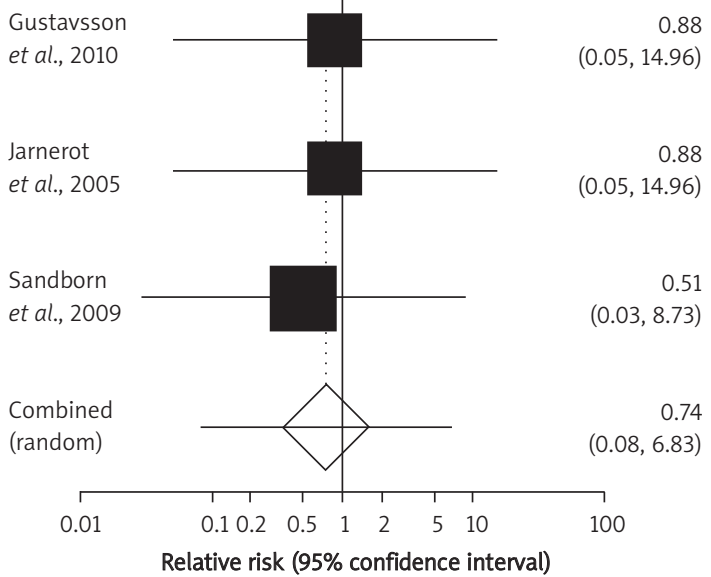

Figure 3 B-a. Individual and pooled relative risk for the outcome of "mortality" in the clinical trials considering IFX vs. placebo therapy

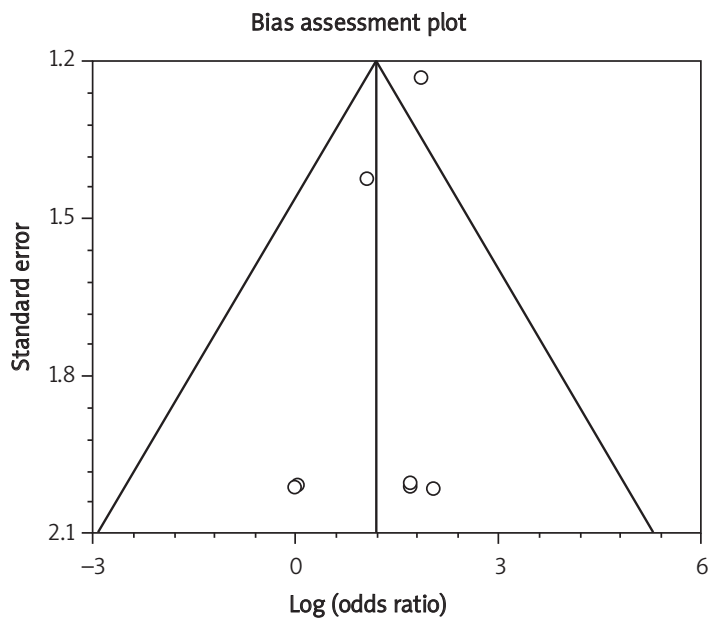

Figure $3 \mathrm{C}$. Publication bias indicators for the outcome of "mortality" in the observational studies considering IFX compared to placebo therapy
L'Abbe plot (symbol size represents sample size)

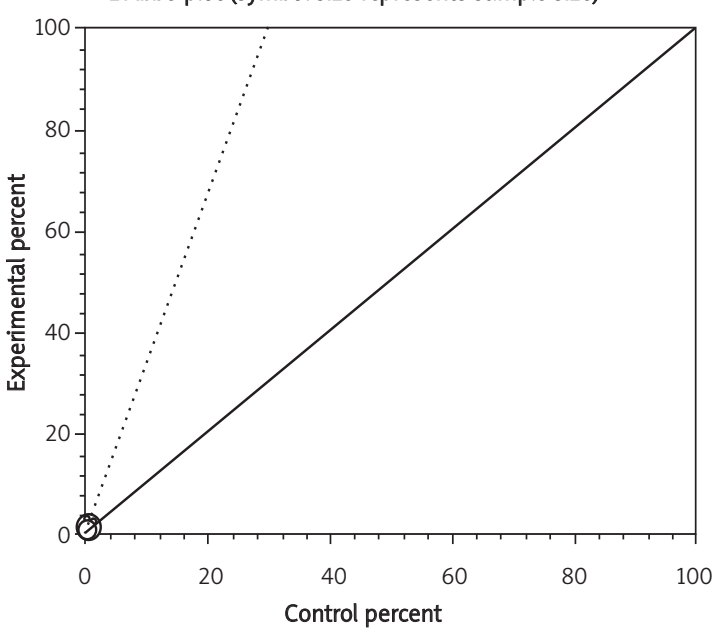

Figure $3 \mathrm{~A}-\mathrm{b}$. Heterogeneity indicators for the outcome of "mortality" in the observational studies considering IFX vs. placebo therapy

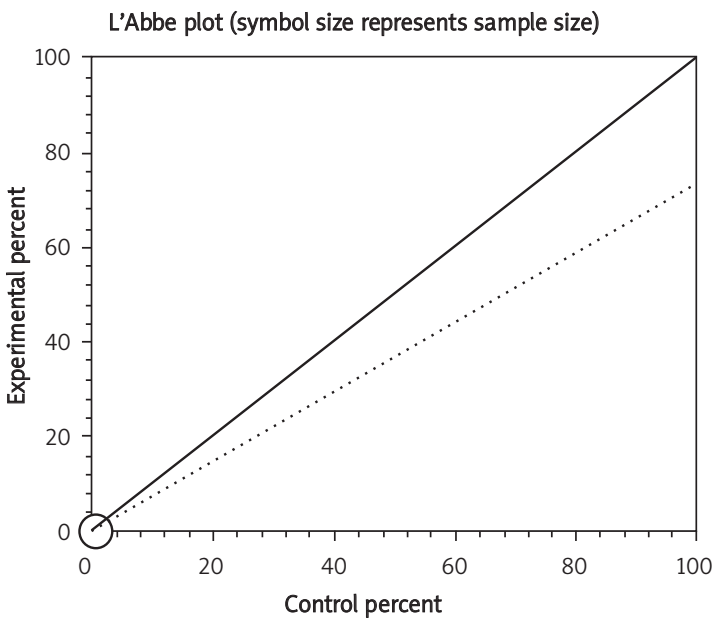

Figure 3 B-b. Heterogeneity indicators for the outcome of "mortality" in the clinical trials considering IFX vs. placebo therapy

ed studies for pouch-related complication among IFX vs. placebo therapy could not be calculated because of too few included studies.

\section{Wound infection}

Summary OR for wound infection in three observational studies $[9,17,21]$ was 1.96 with a $95 \% \mathrm{Cl}$ of 0.84-4.62, a non-significant OR ( $p=0.19)$. The Cochrane $Q$ test for heterogeneity indicated that the studies are not heterogeneous $(p=0.29)$ and could be combined; thus the fixed effects for individual and summary of OR was applied. Regression of normalized effect vs. precision for all included studies in the outcome of wound infection among IFX vs. placebo therapy could not be calculated because of too few included studies. 
Relative risk meta-analysis plot (random effects)

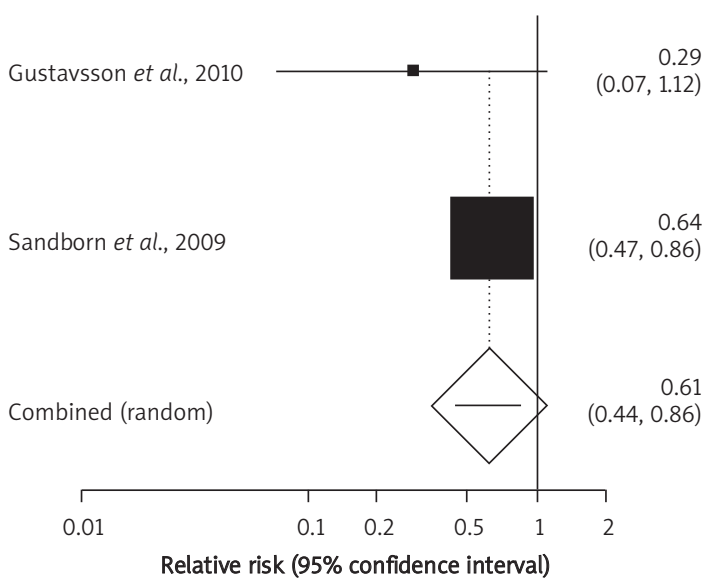

Figure $4 \mathrm{~A}$. Individual and pooled relative risk for the outcome of "hospitalization" in the clinical trials considering IFX vs. placebo therapy

\section{Odds ratio meta-analysis plot (random effects)}

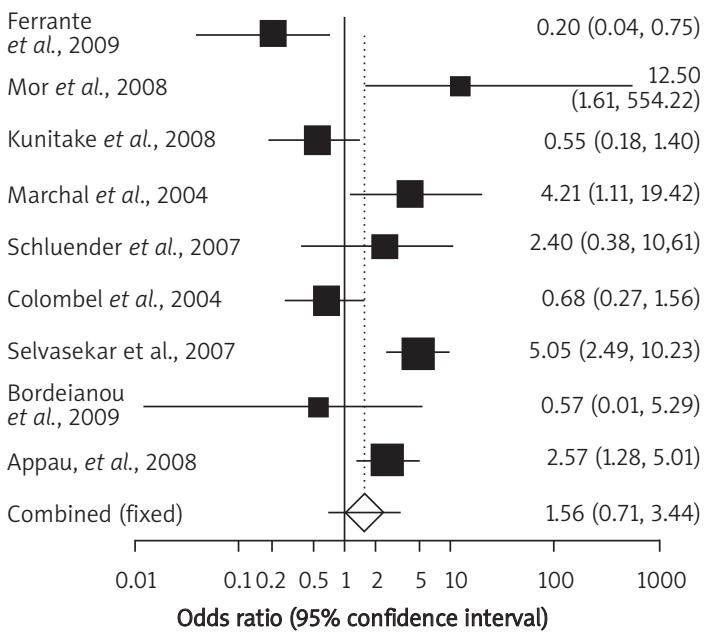

Figure $5 \mathrm{~A}-\mathrm{a}$. Individual and pooled odds ratio for the outcome of "infectious complication" in the observational studies considering IFX vs. placebo therapy

Relative risk meta-analysis plot (random effects)

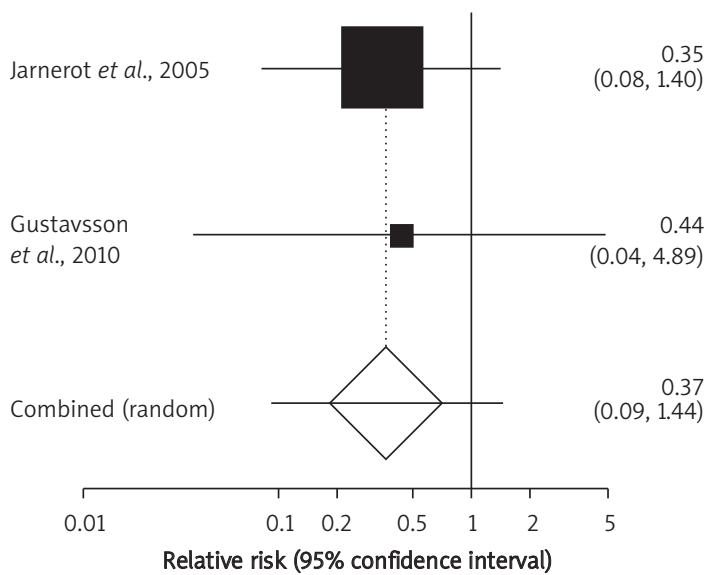

Figure 5 B-a. Individual and pooled odds ratio for the outcome of "infectious complication" in the clinical trials considering IFX vs. placebo therapy
L'Abbe plot (symbol size represents sample size)

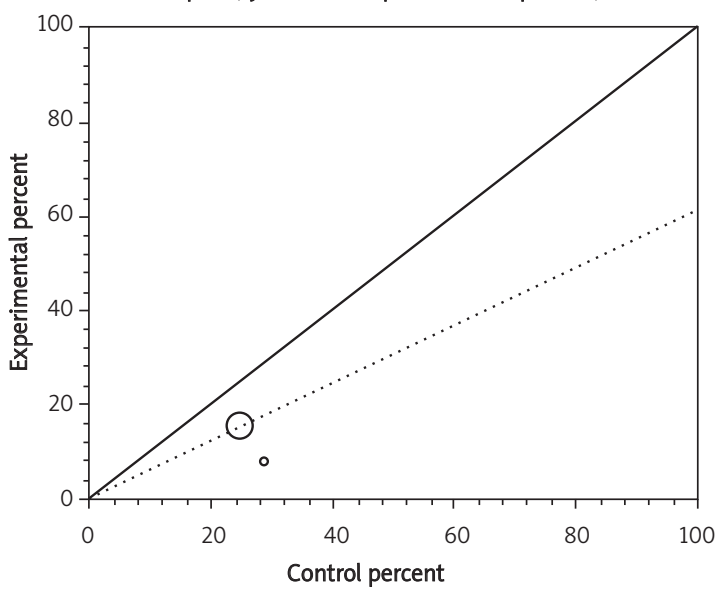

Figure $4 \mathrm{~B}$. Heterogeneity indicators for the outcome of "hospitalization" in the clinical trials considering IFX vs. placebo therapy

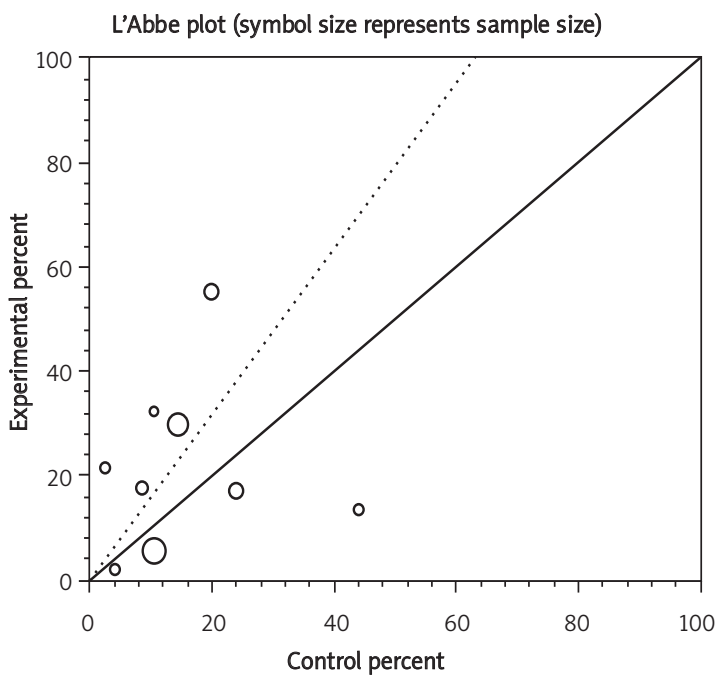

Figure $5 \mathrm{~A}-\mathrm{b}$. Heterogeneity indicators for the outcome of "infectious complication" in the observational studies considering IFX vs. placebo therapy

L'Abbe plot (symbol size represents sample size)

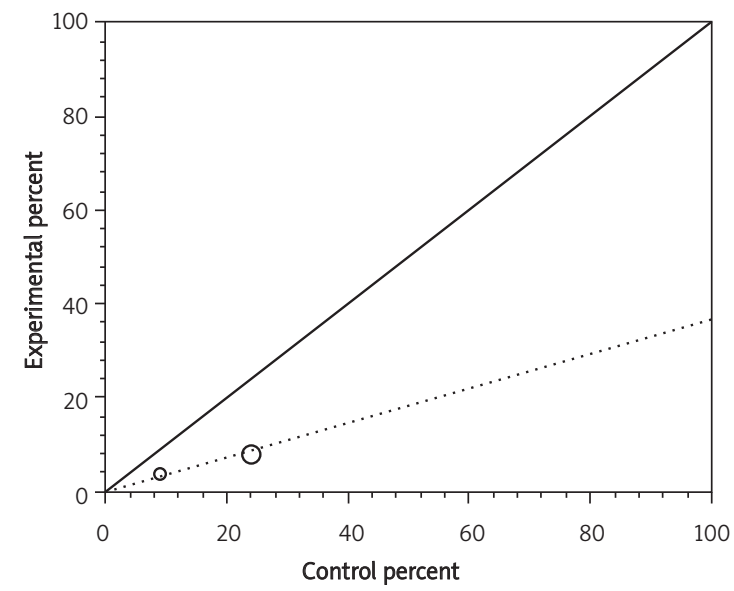

Figure 5 B-b. Heterogeneity indicators for the outcome of "infectious complication" in the clinical trials considering IFX vs. placebo therapy 


\section{Other infections}

Summary OR for other infections in four observational studies $[9,10,17,21]$ was 1.53 with a $95 \% \mathrm{Cl}$ of 0.41-5.67, a non-significant OR $(p=0.53)$. The Cochrane $\mathrm{Q}$ test for heterogeneity indicated that the studies are heterogeneous $(p=0.005)$ and could not be combined; thus the random effects for individual and summary of OR was applied. Regression of normalized effect vs. precision for all included studies in the outcome of other infections among IFX vs. placebo therapy was $-0.65(95 \% \mathrm{Cl}$ $=-13.35$ to $12.05, p=0.85)$ and Kendall's test on standardized effect vs. variance indicated tau $=0$, $p=0.75$.

Summary RR for other infections in two clinical trials $[15,16]$ was 1.06 with a $95 \% \mathrm{Cl}$ of $0.16-6.87$, a non-significant RR $(p=0.95)$. The Cochrane $\mathrm{Q}$ test for heterogeneity indicated that the studies are not

Odds ratio meta-analysis plot (random effects)

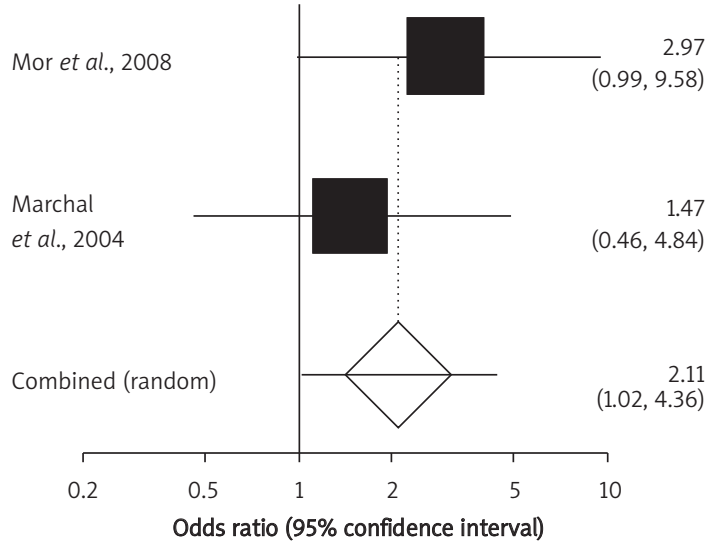

Figure 6 A. Individual and pooled odds ratio for the outcome of "early post-operative complication" in the observational studies considering IFX vs. placebo therapy

Odds ratio meta-analysis plot (random effects)

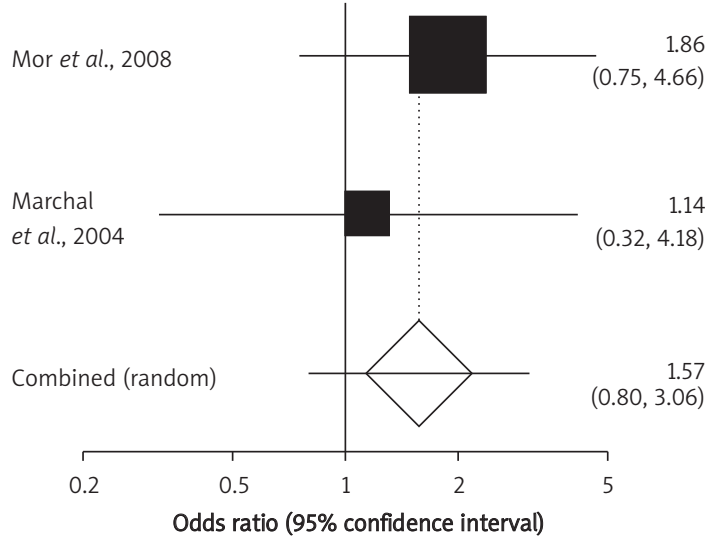

Figure 7 A. Individual and pooled odds ratio for the outcome of "late post-operative complication" in the observational studies considering IFX vs. placebo therapy

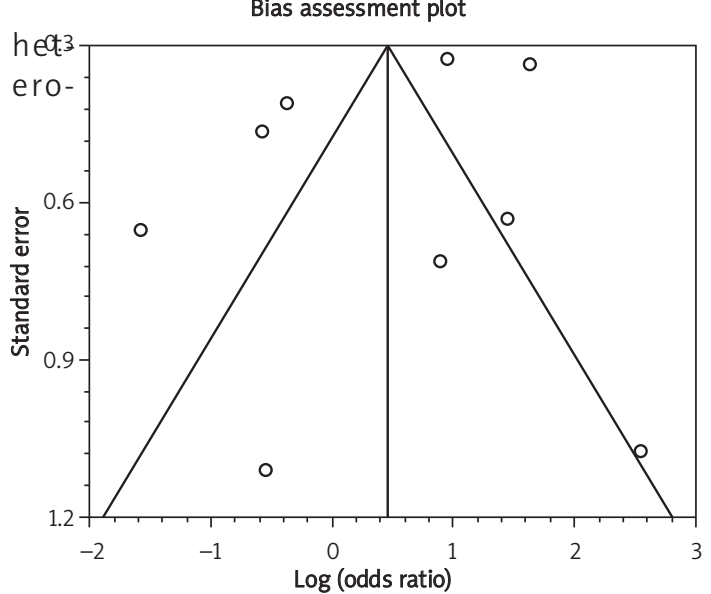

Figure $5 \mathrm{C}$. Publication bias indicators for the outcome of "infectious complication" in the observational studies considering IFX compared to placebo therapy

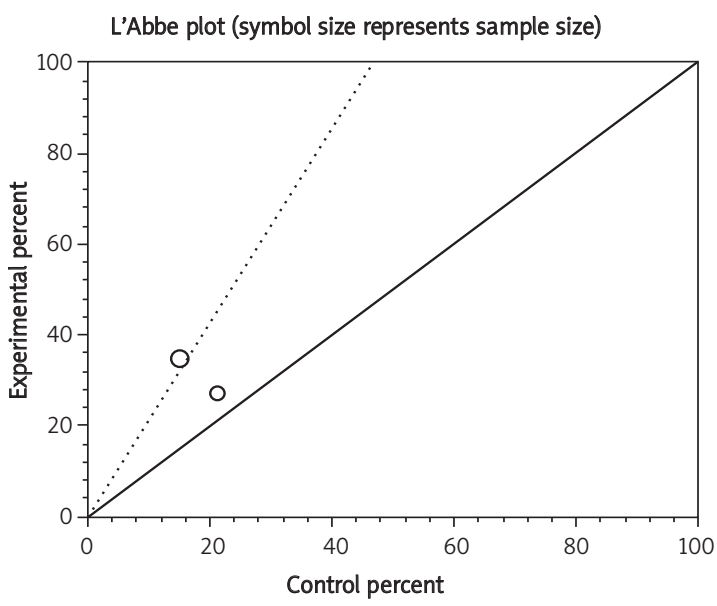

Figure 6 B. Heterogeneity indicators for the outcome of "early post-operative complication" in the observational studies considering IFX vs. placebo therapy

L'Abbe plot (symbol size represents sample size)

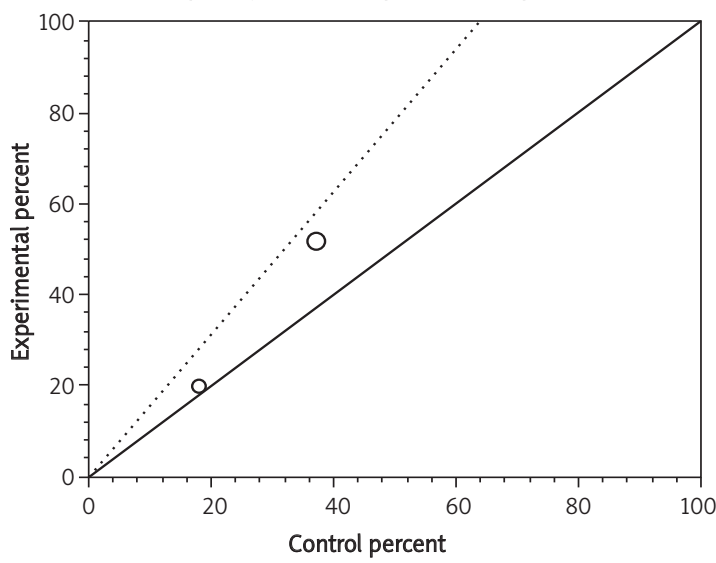

Figure 7 B. Heterogeneity indicators for the outcome of "late post-operative complication" in the observational studies considering IFX vs. placebo therapy 
Table III. Post-operative side effects in patients with IBD who took IFX before operation and those who did not

\begin{tabular}{|lccccc|}
\hline Side effects & $\begin{array}{c}\text { OR/RR combined } \\
\text { meta-analysis }\end{array}$ & $\mathrm{Cl}$ & $\begin{array}{c}\text { Value of } p \\
\text { for OR/RR }\end{array}$ & $\begin{array}{c}\text { Value of } p \\
\text { for heterogeneity }\end{array}$ & $\begin{array}{c}\text { Publication } \\
\text { bias }\end{array}$ \\
\hline Anastomotic leak & OR: 1.71 & $1.02-2.87$ & 0.05 & 0.07 & No \\
\hline Pelvic abscess & OR: 1.09 & $0.17-6.93$ & 0.93 & 0.15 & NA \\
\hline Pouch-related complication & OR: 2.06 & $1.16-3.66$ & 0.023 & 0.054 & NA \\
\hline Wound infection & OR: 1.96 & $0.84-4.62$ & 0.19 & 0.29 & NA \\
\hline Other infections & OR: 1.53 & $0.41-5.67$ & 0.53 & 0.005 & No \\
\cline { 2 - 6 } & RR: 1.06 & $0.16-6.87$ & 0.95 & 0.48 & NA \\
\hline Small intestinal obstruction & OR: 0.44 & $0.12-1.64$ & 0.22 & 0.83 & NA \\
\hline Gl complications & RR: 4.17 & $0.48-35.94$ & 0.19 & 0.96 & NA \\
\hline Sepsis & OR: 1.85 & $1.15-2.97$ & 0.02 & 0.054 & No \\
\hline Postoperative haemorrhage & OR: 2.24 & $0.42-11.85$ & 0.34 & 0.67 & NA \\
\hline Thrombotic event & 4.56 & $1.12-18.53$ & 0.03 & 0.94 & NA \\
\hline Ileus & OR: 0.95 & $0.19-4.68$ & 0.95 & 0.42 & NA \\
\hline Wound failure & 1.27 & $0.15-10.55$ & 0.82 & 0.78 & NA \\
\hline Intra-abdominal abscess & 1.85 & $0.79-4.3$ & 0.16 & 0.5 & NA \\
\hline
\end{tabular}

NA - not applicable

geneous ( $p=0.48$ ) and could be combined but because of few included studies, the random effects for individual and summary of OR was applied. Regression of normalized effect vs. precision for all included studies in the outcome of other infections among IFX vs. placebo therapy could not be calculated because of too few included studies.

\section{Small intestinal obstruction}

Summary OR for small intestinal obstruction in two observational studies $[17,22]$ was 0.44 with a $95 \% \mathrm{Cl}$ of $0.12-1.64$, a non-significant OR $(p=0.22)$. The Cochrane $\mathrm{Q}$ test for heterogeneity indicated that the studies are not heterogeneous ( $p=0.83$ ) and could be combined but because of few included studies the random effects for individual and summary of OR was applied. Regression of normalized effect vs. precision for all included studies in the outcome of small intestinal obstruction among IFX vs. placebo therapy could not be calculated because of too few included studies.

GI complications (nausea, vomiting, dyspepsia, and reflux)

Summary RR for GI complications in two clinical trials $[15,16]$ was 4.17 with a $95 \% \mathrm{Cl}$ of $0.48-35.94$, a non-significant RR $(p=0.19)$. The Cochrane Q test for heterogeneity indicated that the studies are not heterogeneous ( $p=0.96)$ and could be combined but because of few included studies, the random effects for individual and summary of RR was applied. Regression of normalized effect vs. precision for all included studies in the outcome of GI complications among IFX vs. placebo therapy could not be calculated because of too few included studies.

\section{Sepsis}

Summary OR for sepsis in four observational studies $[17,19,20,22]$ was 1.85 with a $95 \% \mathrm{Cl}$ of 1.15-2.97, a significant OR $(p=0.02)$. The Cochrane $\mathrm{Q}$ test for heterogeneity indicated that the studies are not heterogeneous ( $p=0.054)$ and could be combined; thus the fixed effects for individual and summary of OR was applied. Regression of normalized effect vs. precision for all included studies in the outcome of sepsis among IFX vs. placebo therapy was $1.78(95 \% \mathrm{Cl}=-5.2$ to $8.8, p=0.39)$ and Kendall's test on standardized effect vs. variance indicated tau $=0, p=0.75$.

\section{Post-operative haemorrhage}

Summary OR for post-operative haemorrhage in two observational studies [10, 22] was 2.24 with a $95 \% \mathrm{Cl}$ of $0.42-11.85$, a non-significant OR $(p=0.34)$. The Cochrane $\mathrm{Q}$ test for heterogeneity indicated that the studies are not heterogeneous ( $p=0.67)$ and could be combined but because of few included studies the random effects for individual and summary of OR was applied. Regression of normalized effect vs. precision for all included studies in the outcome of postoperative haemorrhage among IFX vs. placebo therapy could not be calculated because of too few included studies. 


\section{Thrombotic event}

Summary OR for thrombotic event in two studies $[10,22]$ was 4.56 with a $95 \% \mathrm{Cl}$ of $1.12-18.53$, a significant OR $(p=0.03)$. The Cochrane $\mathrm{Q}$ test for heterogeneity indicated that the studies are not heterogeneous ( $p=0.94)$ and could be combined but because of few included studies, the random effects for individual and summary of OR was applied. Regression of normalized effect vs. precision for all included studies in the outcome of thrombotic event among IFX vs. placebo therapy could not be calculated because of too few included studies.

\section{Ileus}

Summary OR for ileus in two observational studies [17, 22] was 0.95 with a $95 \% \mathrm{Cl}$ of 0.19 4.68 , a non-significant OR $(p=0.95)$. The Cochrane $\mathrm{Q}$ test for heterogeneity indicated that the studies are not heterogeneous $(p=0.42)$ and could be combined but because of few included studies, the random effects for individual and summary of OR was applied. Regression of normalized effect Vs. precision for all included studies in the outcome of ileus among IFX vs. placebo therapy could not be calculated because of too few included studies.

\section{Wound failure}

Summary OR for wound failure in two studies $[17,20]$ was 1.27 with a $95 \% \mathrm{Cl}$ of $0.15-10.55$, a nonsignificant OR $(p=0.82)$. The Cochrane Q test for heterogeneity indicated that the studies are not heterogeneous ( $p=0.78)$ and could be combined but because of few included studies, the random effects for individual and summary of OR was applied. Regression of normalized effect vs. precision for all included studies in the outcome of wound failure among IFX vs. placebo therapy could not be calculated because of too few included studies.

\section{Intra-abdominal abscess}

Summary OR for intra-abdominal abscess in three studies $[11,17,20]$ was 1.85 with a $95 \% \mathrm{Cl}$ of $0.79-4.3$, a non-significant OR $(p=0.16)$. The Cochrane $\mathrm{Q}$ test for heterogeneity indicated that the studies are not heterogeneous $(p=0.5)$ and could be combined but because of few included studies, the random effects for individual and summary of OR was applied. Regression of normalized effect vs. precision for all included studies in the outcome of intra-abdominal abscess among IFX vs. placebo therapy could not be calculated because of too few included studies.

\section{Discussion}

The present meta-analysis found that there is no significant difference in the rate of colectomy in the patients with UC who received IFX in comparison to the patients who did not receive IFX. Mortality was not significantly different between the two groups either. However, the level of postoperative hospitalization in patients who were under IFX therapy was lower than in the control group.

There has been no meta-analysis addressing the effect of IFX therapy on the rate of colectomy. Wihelm et al. mentioned the efficacy of IFX in their review [23]. However, among the articles included in that review, only Jarnerot et al. studied the effect of IFX on the rate of colectomy and found that $21 \%$ of the IFX group required colectomy within the first 90 days after treatment in comparison to $67 \%$ in the placebo group ( $p=0.017)$ [16]. Gustavsson et al. found that colectomy in short term (3 months) and also long term (3 years) is reduced in the IFX group with a colectomy frequency of $50 \%$ as compared with $76 \%$ in the placebo group in 3 years [15]. However, most of the colectomies were performed during the first 3 months. In the cohort of Schluender et al., two out of 17 patients in the IFX group and 37 out of 134 patients in the non-IFX group underwent colectomy [18]. The RCT of Sandborn et al. showed that patients with moderate to severe UC treated with IFX were less likely to undergo colectomy during 54 weeks than those receiving placebo despite concurrent medication. However, that trial due to the long period of follow-up was limited by the colectomy follow-up [12]. Several uncontrolled studies showed that the rate of colectomy in patients under IFX therapy is less than $50 \%$ [24-27]. However, those studies had different duration of follow-up and no control groups. This indicates that for more accurate results on the efficacy of IFX in the rate of colectomy, more controlled trials should be performed.

This meta-analysis also found that overall early post-operative complications were more frequent among patients who received IFX pre-operatively. However, overall infectious complications in clinical trials and also observational studies were not significantly different between patients who were treated with IFX and those who were not. Among side effects, anastomotic leak, pouch-related complications, sepsis and particularly thrombotic events were significantly more common in patients who were treated with IFX pre-operatively. There is a meta-analysis on the effect of IFX on short-term post-operative complications in patients with UC demonstrating that short-term complications increase with the use of IFX but infectious complications and non-infectious complications do not 
significantly increase [13]. Selvasekar et al. found a significantly increased risk for post-operative pouch-specific and infectious complications in 47 UC patients who had been treated with IFX before ileal pouch anal anastomosis compared to 254 control patients. Confounding factors such as age, severity of colitis, concomitant use of immunomodulatory drugs, and corticosteroids were adjusted and still IFX remained an independent predictor of infections [21]. Schluender et al. did not find any significant difference in overall post-operative or infectious complications between 17 UC patients who had been treated with IFX before surgery and 134 control patients [18]. Mor et al. found that the covariate adjusted odds ratio of early complication for 85 patients with UC or indeterminate colitis in the IFX group was 3.54 times higher than that of 523 patients in the control group [22]. Kunitake et al., who evaluated patients with UC, CD, and indeterminate colitis, did not find any significant difference in development of post-operative infectious complications in 101 patients treated with IFX and 312 patients not treated [10].

Appau et al. found that pre-surgical treatment with IFX in patients with CD is associated with increased post-operative sepsis, abscess and readmissions [20]. However, Marchal et al. showed that IFX therapy in patients with CD did not increase the rate of post-operative complications in comparison to patients who did not take IFX [17].

To overcome heterogeneity in our meta-analysis, we pooled studies that assessed UC and CD for post-operative complications. However, the rate of colectomy was only analysed in the patients with UC because CD patients rarely undergo isolated colectomy. Combining the patients with UC and the patients with $C D$ in the analyses may have an influence on the results because of their different clinical course, but there is evidence [10] that the difference in the rate of IFX-associated complications between UC and CD patients is not significant. We analysed clinical trials and observational studies separately. Although observational studies are more realistic, bias is more frequent. On the other hand, the internal validity in RCTs is higher and the external validity is lower. However, we did not find a large difference in the results of observational studies vs. clinical trials. In the mortality and infectious complications, the results were opposite. In the observational studies, mortality and infectious complications were more frequent in the patients under IFX therapy. However, the meta-analysis of both types showed that the differences are not significant in these two variables.

In the included studies, there were some kinds of bias such as unclear duration of IFX therapy and/or concomitant therapies and/or the dosage of IFX that inevitably might affect the results of the meta-analysis. For instance, in some studies, such as those of Mor et al. [22], Marchal et al. [17], and Selvasekar et al. [21], all the patients who had ever been treated with IFX were included in the IFX group regardless of the duration of treatment before surgery. Concomitant drugs may also influence the post-surgical complications such as serious infection seen in CD patients who had been treated with IFX in combination with corticosteroids or narcotic analgesics [28]. In fact, in the majority of the studies that assessed the safety of anti-TNF drugs, the majority of patients were receiving concomitant immunomodulators or corticosteroids that may have increased the risk of opportunistic infection [29]. Moreover, Ferrante et al. found that a moderate-to-high dose of corticosteroids but not IFX is associated with short-term post-operative infectious complications [9]. It is notable that microbial infection has a fundamental role in pathogenesis of IBD that cannot be neglected and thus most current management protocols for $\operatorname{IBD}[30,31]$ and other forms of colitis [32] suggest the use of antibiotics. Of course, the matter of cytokines and inflammation is too complex. For instance, production of cytokines in chronic inflammation prevents further enhancement of cytokine synthesis triggered by surgery and other normal physiological responses may play roles [33].

Despite some recorded heterogeneity in our meta-analysis, no publication bias was found in the analysis. Funnel plot analysis was used as a publication bias indicator. Funnel plots, that is simple scatter plots of the trials' effect, estimate their sample size in detecting any bias in the meta-analysis. The funnel plot is based on the fact that precision in estimating the underlying treatment effect will increase as the sample size of component studies increases. Results from small studies will scatter widely at the bottom of the graph. The spread will narrow as precision increases among larger studies. In the absence of bias, the plot should thus resemble a symmetrical inverted funnel [34].

In conclusion, this meta-analysis revealed that although IFX use neither decreases the rate of colectomy nor increases the rate of infectious complications in IBD patients, thrombotic events, ileal pouch complications, sepsis and anastomotic leaks are the complications that were increased in the patients who used IFX. On the other hand, postoperative hospitalization is less frequent in the patients under IFX therapy. The patients with IBD who are under IFX therapy are most of the time refractive to other therapies and their disease is in a severe stage. Thus it is possible that the postoperational complications in the IFX group are associated with the severity of the disease, and while the studies that are included in the meta-analysis 
are heterogeneous, we cannot consider this as an exclusive result of IFX.

Further clinical trials on the efficacy of IFX in patients with CD and on different types of surgery in patients with IBD are needed for more accurate results.

\section{Acknowledgments}

This paper is the outcome of an in-house nonfinancially supported study and the authors have no conflict of interest.

\section{References}

1. Matricon J, Barnich N, Ardid D. Immunopathogenesis of inflammatory bowel disease. Landes Bioscience 2010; Self/Nonself 1:4: 299-309.

2. Rezaie A, Parker RD, Abdollahi M. Oxidative stress and pathogenesis of inflammatory bowel disease: an epiphenomenon or the cause? Dig Dis Sci 2007; 52: 2015-21.

3. Nikfar S, Rahimi R, Rezaie A, Abdollahi M. A meta-analysis of the efficacy of sulfasalazine in comparison with 5 -aminosalicylates in the induction of improvement and maintenance of remission in patients with ulcerative colitis. Dig Dis Sci 2009; 54: 1157-70.

4. Rahimi R, Nikfar S, Rezaie A, Abdollahi M. Comparison of mesalazine and balsalazide in induction and maintenance of remission in patients with ulcerative colitis: a metaanalysis. Dig Dis Sci 2009; 54: 712-21.

5. Rahimi R, Nikfar S, Abdollahi M. Meta-analysis technique confirms the effectiveness of anti-TNF in the management of active ulcerative colitis when administered in combination with corticosteroids. Med Sci Monit 2007; 13: PI13-18.

6. Nikfar S, Ehteshami-Afshar S, Abdollahi M. A systematic review and meta-analysis of the efficacy and adverse events of Infliximab in comparison to corticosteroids and placebo in active ulcerative colitis. Int J Pharmacol 2011; 7: 325-32.

7. Rahimi R, Nikfar S, Abdollahi M. Do anti-tumor necrosis factors induce response and remission in patients with acute refractory Crohn's disease? A systematic metaanalysis of controlled clinical trials. Biomed Pharmacother 2007; 61: 75-80.

8. Hancock L, Mortensen NJ. How often do IBD patients require resection of their intestine? Inflamm Bowel Dis 2008; 14 (Suppl 2): S68-9.

9. Ferrante M, D'Hoore A, Vermeire S, et al. Corticosteroids but not infliximab increase short-term postoperative infectious complications in patients with ulcerative colitis. Inflamm Bowel Dis 2009; 15: 1062-70.

10. Kunitake H, Hodin R, Shellito PC, et al. Perioperative treatment with infliximab in patients with Crohn's disease and ulcerative colitis is not associated with an increased rate of postoperative complications. J Gastrointest Surg 2008; 12: 1730-6

11. Bordeianou L, Kunitake H, Shellito P, Hodin R. Preoperative infliximab treatment in patients with ulcerative and indeterminate colitis does not increase rate of conversion to emergent and multistep abdominal surgery. Int J Colorectal Dis 2010; 25: 401-4.

12. Sandborn WJ, Rutgeerts P, Feagan BG, et al. Colectomy rate comparison after treatment of ulcerative colitis with placebo or infliximab. Gastroenterology 2009; 137: 1250-60.
13. Yang Z, Wu Q, Wu K, Fan D. Meta-analysis: pre-operative infliximab treatment and short-term post-operative complications in patients with ulcerative colitis. Aliment Pharmacol Ther 2010; 31: 486-92.

14. Jadad AR, Enkin MW. Randomised controlled trials. 2nd ed. London, United Kingdom: BMJ Books 2007.

15. Gustavsson A, Järnerot G, Hertervig E, et al. Clinical trial: colectomy after rescue therapy in ulcerative colitis 3-year follow-up of the Swedish-Danish controlled infliximab study. Aliment Pharmacol Ther 2010; 32: 984-9.

16. Järnerot G, Hertervig E, Friis-Liby I, et al. Infliximab as rescue therapy in severe to moderately severe ulcerative colitis: a randomized, placebo-controlled study. Gastroenterology 2005; 128: 1805-11.

17. Marchal L, D'Haens G, Van Assche G, et al. The risk of postoperative complications associated with infliximab therapy for Crohn's disease: a controlled cohort study. Aliment Pharmacol Ther 2004; 19: 749-54.

18. Schluender SJ, Ippoliti A, Dubinsky M, et al. Does infliximab influence surgical morbidity of ileal pouch-anal anastomosis in patients with ulcerative colitis? Dis Colon Rectum 2007; 50: 1747-53.

19. Colombel JF, Loftus EV Jr, Tremaine WJ, et al. Early postoperative complications are not increased in patients with Crohn's disease treated perioperatively with infliximab or immunosuppressive therapy. Am J Gastroenterol 2004; 99: 878-83.

20. Appau KA, Fazio VW, Shen B, et al. Use of infliximab within 3 months of ileocolonic resection is associated with adverse postoperative outcomes in Crohn's patients. J Gastrointest Surg 2008; 12: 1738-44.

21. Selvasekar CR, Cima RR, Larson DW, et al. Effect of infliximab on short-term complications in patients undergoing operation for chronic ulcerative colitis. J Am Coll Surg 2007; 204: 956-62.

22. Mor IJ, Vogel JD, da Luz Moreira A, et al. Infliximab in ulcerative colitis is associated with an increased risk of postoperative complications after restorative proctocolectomy. Dis Colon Rectum 2008; 51: 1202-7.

23. Wilhelm SM, McKenney KA, Rivait KN, Kale-Pradhan PB. A review of infliximab use in ulcerative colitis. Clin Ther 2008; 30: 223-30.

24. Bressler B, Law JK, Al-Nahdi-Sheraisher N, et al. The use of infliximab for treatment of hospitalized patients with acute severe ulcerative colitis. Can J Gastroenterol 2008; 22: 937-40.

25. Aratari A, Papi C, Clemente V, et al. Colectomy rate in acute severe ulcerative colitis in the infliximab era. Dig Liver Dis 2008; 40: 821-6.

26. Kohn A, Daperno M, Armuzzi A, et al. Infliximab in severe ulcerative colitis: short-term results of different infusion regimens and long-term follow-up. Aliment Pharmacol Ther 2007; 26: 747-56.

27. Lees CW, Heys D, Ho GT, et al. A retrospective analysis of the efficacy and safety of infliximab as rescue therapy in acute severe ulcerative colitis. Aliment Pharmacol Ther 2007; 26: 411-9.

28. Shen B. Impact of preoperative infliximab use on postoperative infectious complications in ulcerative colitis: the price we have to pay? Inflamm Bowel Dis 2008; 14: 1019-21.

29. Mshale MJ, Seow CH, Coffin CS, et al. Review article: chronic viral infection in the anti-tumour necrosis factor therapy era in inflammatory bowel disease. Aliment Pharmacol Ther 2010; 31: 20-34. 
30. Nikfar S, Mirfazaelian H, Abdollahi M. Efficacy and tolerability of immunoregulators and antibiotics in fistulizing Crohn's disease: a systematic review and metaanalysis of placebo-controlled trials. Curr Pharm Des 2010; 16: 3684-98.

31. Nikfar S, Darvish-Damavandi M, Abdollahi M. A review and meta-analysis of the efficacy of antibiotics and probiotics in management of pouchitis. Int J Pharmacol 2010; 6: 826-35.

32. Rezaie A, Nikfar S, Abdollahi M. The place of antibiotics in management of irritable bowel syndrome: a systematic review and meta-analysis. Arch Med Sci 2010; 6: 49-55.

33. Lisowska B, Maśliński W, Małdyk P. Perioperative inflammatory response in patients with rheumatoid arthritis undergoing orthopaedic surgery. Arch Med Sci 2009; 5: 248-54.

34. Egger M, Smith GD, Altman DG. Systematic reviews in health care: meta-analysis in context. 2 nd ed. London, United Kingdom, BMJ Books 2001. 